\title{
The Teaching Reform of Humanities Courses Based on the Cultivation of Professional Chinese Ability
}

\author{
Yi Xiaohui \\ Nanchang Institute of Science \&Technology,Nanchang 330108,China
}

\begin{abstract}
Keywords: Humanities curriculum reform; application; professional Chinese ability training model;
\end{abstract} social talent

\begin{abstract}
After forecast, calculation and analysis, the shortage of talents in social market mainly lies in the related humanities fields. And through the survey found that school humanities curriculum has a lot of problems, such as: too few courses in related fields, practice ability culture curriculum scarce, and lack of the field of in-depth study of the teachers teaching guide etc.. According to the analysis of these reasons, it is necessary to reform and renew the humanities courses, in order to adapt to the training of professional Chinese ability, and to improve the number of students in the field of engineering. And the humanities courses instability such facts, namely the lack of interest in the field of professional training of teachers and curriculum, especially relates to professional teaching training, data obtained through the investigation result is: $79 \%$ of teachers in their field of study did not participate in the graduate course training, only $30 \%$ participated in the continuous training courses. Therefore, we must according to the society to talented person's demand characteristic of timely to humanities teaching curriculum reform, to keep pace with the times, in order to keep up with the pace of social development, in order to cultivate outstanding talents to adapt to the society. The results of this study reflect the current social demand for talent is still huge total, of which the requirements of engineering and humanities personnel are relatively large, followed by the management staff. This suggests that with the development of economy, of Social Sciences in the field of talent still require very high, so must humanities teaching reform to improve the quality of teaching, training to adapt to the vocational Chinese competence.
\end{abstract}

\section{Introduction}

The rapid development of society has brought economic growth, and the demand for talents is also growing. While more people are currently receiving higher education, expecting to be the talents needed by the community and able to realize their own value to create wealth for society. However, this not only requires their continuous learning efforts, but also the correct guidance of the school education. But the actual situation is not optimistic at all, with many teachers uncertain of the current social situation, and the school training programs not meeting the needs of social development[1-3]. Therefore, this paper integrates demand features of social unit or enterprise, uses related mathematical theory for forecasting social talent demand and establishing social demand model. Based on the results of the research to adjust education curriculum, education and teaching reform can be achieved[4,5].

\section{Education and teaching analysis}

According to the data report of the Ministry of Education, school organizes teachers each year to participate in five courses training activities at least three times a year or more. School is committed to the development of teaching and training in the field, with more than 80 percent of the teachers attending training courses in their respective fields[6-10].

In this case, the quality of education and teaching does not improve at all. We can draw a conclusion based on this mismatch for the needs of the society: (1) The various training programs teachers participate in are inappropriate; (2) These training courses are not going through social needs analysis. This kind of training course is only to allow participants to obtain the so-called teaching scores. In fact, we can assert that the education system has never made any attempt to reform the 
teacher training model. Therefore, those who have no responsibility to shoulder seems to have no right to make the decision to change the curriculum[11-13]. Policy-makers can develop a reform project, but due to the lack of front-line teaching experience, they have no concept on courses especially those courses meeting social needs. For this reason, many new courses urgently need to be changed but most have been rejected, and the progress of the education curriculum reform stalled.

\section{Talent demand forecasting model}

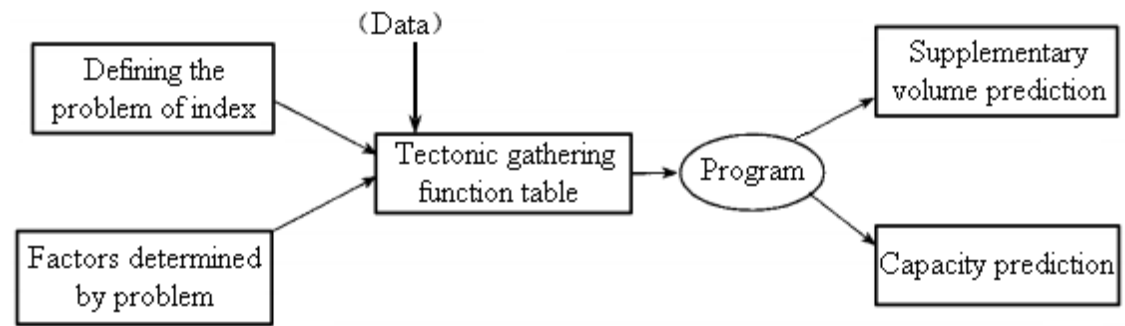

Fig 1 block diagram of talent demand forecast

Steps in Factor reconstruction analysis calculation

1) Calculate the maximum and minimum values of the degree of importance of the social demand for talent[14]:

$$
\min \Phi_{, l}=\sum_{n=1}^{N} \min _{L_{n} \in d_{n}} e d c^{*}\left(K, L_{k}, n, L_{n}\right)
$$

2) Calculate the actual proximity of indicators in years in prediction[15]:

3) Trend forecast[16]:

$$
\begin{aligned}
& \Phi_{k, l_{k}}(T)=\frac{\Phi_{k, l_{k}}(T)-\min \Phi_{k, l_{k}}}{\max \Phi_{i, l_{k}}-\min \Phi_{k, l_{k}}} \\
& W_{2}(T)=\frac{\Phi_{1,}(T) \cdot E_{0}^{\prime}+\Omega_{2,2}(T) E_{1}^{\prime} \cdot \Omega_{2,2}(T) \cdot E_{2}^{\prime}}{\Phi_{2,1}(T)+\Omega_{2,2}(T)+\Omega_{2,3}(T)}
\end{aligned}
$$

Forecasting the social demand for talents entails the speed and scale of the development of national economy, the intensity of industrial structure, direction, and the proportion of high-tech industry in the overall industry and many other factors. The demand characteristics of talent and training system will be changed greatly. Therefore, there is an urgent need to study the demand characteristics of the social talents. As the demand for talents stems from the economic development, economic development scale, structure, and environment in different periods have a different talent development speed. Through data analysis, the total talents demand forecast from 2002 to 2010 can be drawn in Table 1 . 
Table 1 Social demand for talents and its influencing factors

\begin{tabular}{|l|l|l|l|l|l|l|l|l|}
\hline & $\begin{array}{l}\text { Talent } \\
\text { demand } \\
\text { rate\% }\end{array}$ & $\begin{array}{l}\text { the } \\
\text { growth } \\
\text { rate of } \\
\text { GDP\% }\end{array}$ & $\begin{array}{l}\text { the } \\
\text { proportion } \\
\text { of the first } \\
\text { industry\% }\end{array}$ & $\begin{array}{l}\text { the } \\
\text { proportion } \\
\text { of the } \\
\text { second } \\
\text { industry\% }\end{array}$ & $\begin{array}{l}\text { the } \\
\text { proportion } \\
\text { of the } \\
\text { third } \\
\text { industry\% }\end{array}$ & $\begin{array}{l}\text { the } \\
\text { proportion of } \\
\text { high and } \\
\text { new } \\
\text { technology\% }\end{array}$ & $\begin{array}{l}\text { social labor } \\
\text { productivity } \\
\text { growth } \\
\text { rate\% }\end{array}$ & $\begin{array}{l}\text { talent } \\
\text { development } \\
\text { social } \\
\text { environment }\end{array}$ \\
\hline 2006 & 7.84 & 6 & 8.55 & 56.7 & 34.7 & 3.7 & 3.9 & very good \\
\hline 2007 & 3.72 & 11.8 & 7.36 & 56.1 & 36.3 & 5.4 & 10.2 & preferably \\
\hline 2008 & 1.91 & 12.2 & 6.7 & 56.1 & 45.7 & 7.3 & 8.4 & commonly \\
\hline 2009 & 8.05 & 14.4 & 6.42 & 55.2 & 43.6 & 10.1 & 12.2 & very good \\
\hline 2010 & 2.8 & 14.8 & 6.88 & 55.5 & 43.6 & 12.3 & 14.5 & preferably \\
\hline 2011 & -1.34 & 14.4 & 6.4 & 53.0 & 32.5 & 14.2 & 15.3 & commonly \\
\hline 2012 & -2.07 & 12.4 & 6.02 & 51.2 & 45.1 & 16.3 & 11.8 & commonly \\
\hline 2013 & 5.5 & 9.7 & 4.7 & 40.9 & 37.9 & 25.1 & 12.7 & preferably \\
\hline 2014 & 5 & 12.8 & 2.27 & 52.2 & 37.3 & 13.3 & 16.4 & preferably \\
\hline 2015 & 5.4 & 19.5 & 1.7 & 50.5 & 36.8 & 35.1 & 10.4 & preferably \\
\hline
\end{tabular}

The above data shows that the use of factor reconstruction analysis method to analyze the important trend of the talents demand from 2006 to 2015, which is shown in Fig 2.

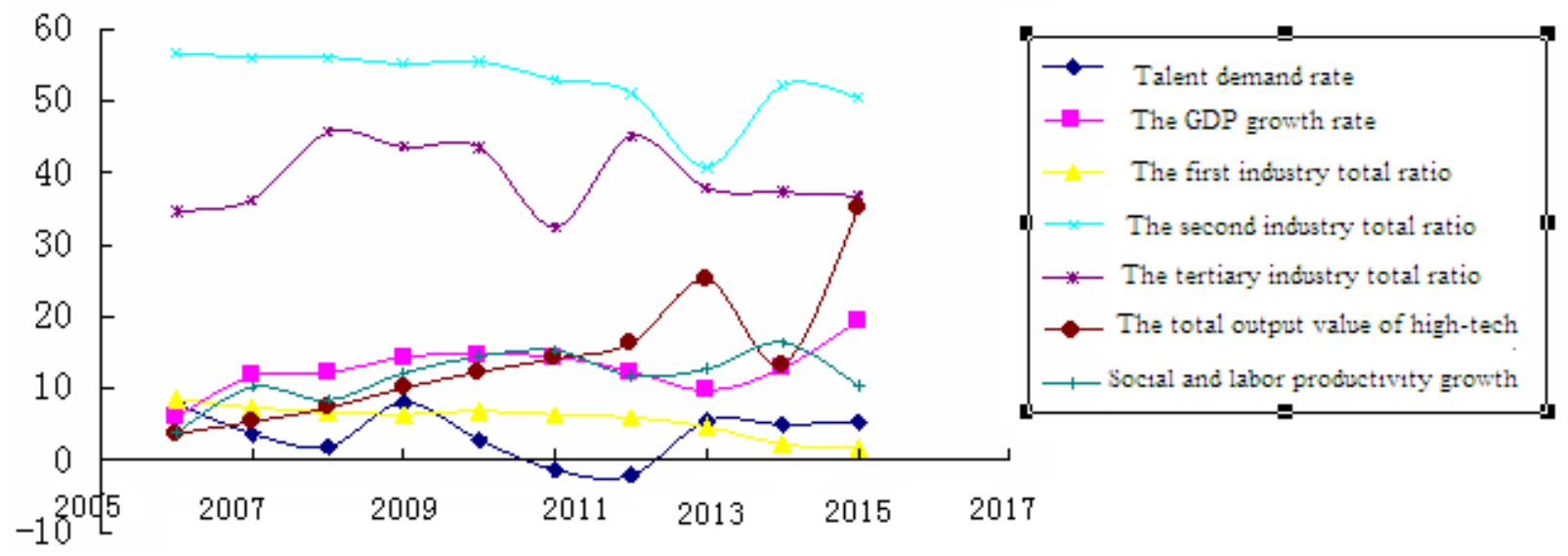

Fig 2 the import trends of various factors on the demand for talents

\section{Societal Demands for Talents Analysis}

In order to increase the specific analysis of the characteristics of the social demand for talents, by using the above established model to make mathematical calculations, and analyze the current field of social talents required based on survey data. According to the model formula[17]:

$$
E_{m}=\frac{\Delta G D P / G D P}{\Delta n / m}
$$

The proportion of domestic demand for talent and talent quality indicators can be drawn from the formula.

According to the model formula[18]:

$$
A=\frac{E_{\text {m }}^{2}}{E_{m}^{1}}-1
$$

The magnitude of the demand for talent can be calculated form the formula.

According to the survey results and predictions, the social demand for talents, and talent structure and quality, it can be calculated in Table 2. 
Table 2 talent demands, talent structure and talent quality forecast results

\begin{tabular}{|c|c|l|l|l|}
\hline Year & $\begin{array}{c}\text { Total talent } \\
\text { demands }\end{array}$ & \multicolumn{1}{|c|}{ talent structure } & talent quality \\
\cline { 3 - 4 } & $\begin{array}{l}\text { Engineering } \\
\text { humanities } \\
\text { personnel }\end{array}$ & $\begin{array}{c}\text { Administrative } \\
\text { staff }\end{array}$ & \\
\hline 2006 & 26356 & 8636 & 7720 & $/$ \\
\hline 2008 & 33287 & 12120 & 11167 & 2.87 \\
\hline 2011 & 47551 & 14339 & 13212 & $/$ \\
\hline 2015 & 32596 & 16965 & 15631 & 3.19 \\
\hline
\end{tabular}

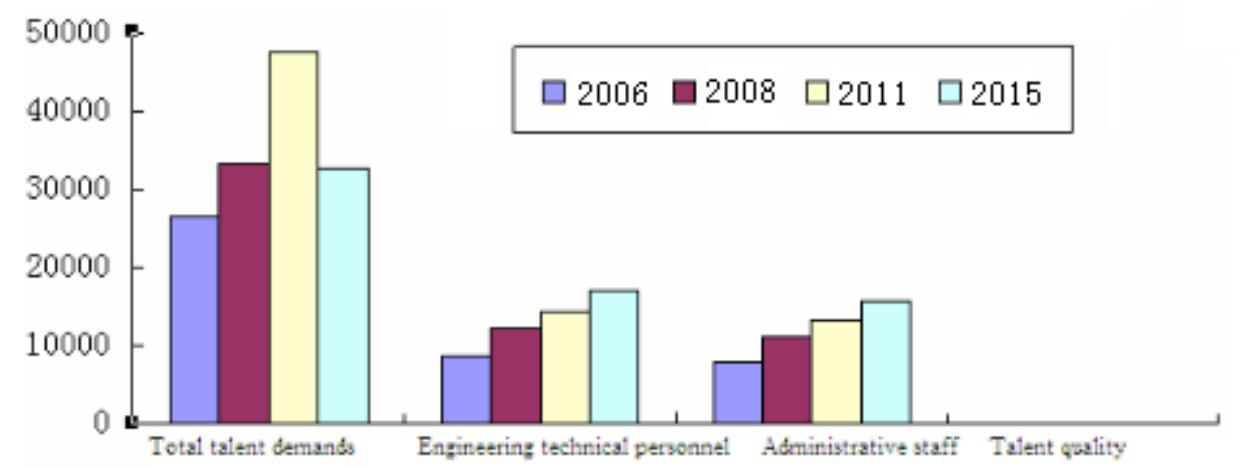

Fig 3 trends of the social talent demands characteristic

\section{Conclusion}

Studies have shown that there is a common problem in the course of Humanities: Although many teachers to participate in the training courses. However, the results of the study show disappointing results when the students have completed undergraduate humanities courses and humanities courses. From the need to solve this contradiction, the social talent demand forecast analysis, can provide the latest teaching strategies and methods to improve the teaching of humanities courses in the humanities courses of interest and humanities curriculum responsibility. At the same time, the establishment of professional Chinese ability training model to analyze the characteristics of the demand for talents, to vocational Chinese competence training for the purpose of humanities curriculum reform, and the setting of the target program, humanities teaching reform to improve the beneficial reference.

\section{References}

[1] Tingyong Feng,Li Hong. The contemporary college students learning adaptability of preliminary study - Exploration of psychology,2002 (1).

[2] Xie Feng Lou.College student's social adaptation scale and standardization 2003

[3] XiaoguangYue.The Party School Physical Education in Yunnan Province during the students' Social Adaptability. Training Research, 2006(12).

[4] Yu Lin.The college students' social adaption.Psychological Health.Modern life,2007(2).

[5] Xuejun Da.The problem analysis and Countermeasure of college student's social adaptation ability. Journal of Huaiyin Institute of Technology, 2009 (6).

[6] XiaoYang.The effects on college Students' ability of social adaptation.Modern enterprise education, 2009 (12) 
[7] Jinyan Luo. College students employment and social adaptation ability of campus culture under the financial crisis. Southern Journal, 2009 (5).

[8] XiuyunYin. College students' Setback causes analysis and anti frustration education. Cultural and educational information, 2007 (23).

[9] LishengChen, WenpeiZhuang. The problem of the social adaptability of college students.Ideological and political education research 2007 ( 3).

[10] Lixiong Zhao.The understanding of social integration social adaptation social -- talking with college students about social issue .Journal of Qujing Normal University, 2009 ( 1).

[11] bin Ze,Chen Yue. The Multi-campus University Freshmen's adaptation to the educational study.School of Party construction and Ideological Education (Higher Education Edition ),2011 ( 1).

[12] Jun Guo. Wenhui You. Study on sociology personnel occupation adaptation ability. Journal of Chengdu University of Technology,2008 (4).

[13] Binghong Li, HuiChen, Gang Ni. college student occupation career planning education for college graduates and social adaptation ability training effect .Journal of Guangdong University of Technology,2010 ( z1)

[14] Dayou Shi, Weixin Jia, Xiaomei Chen. How to strengthen social practice activities and improve the students' ability to adapt the society relationship .Technology Monthly,2008 (3).

[15] Xiong Ying, Dong Dakui. Case studies and inspiration on talents training mode of humanities undergraduate. [J]. Education Forum, 2010 (6).

[16] Bian Xu, Forecasting method for stimulating demand for talents [J]. Northeastern University, 1998,19 (4),428-431.

[17] Shi Feng, Training model of the modern service industry cultivating high-quality personnel in innovative capita [J], Beijing Education, 2010 (3).

[18] Weixian Qi, The design and realization of a talent forecasting system [J]. Microcomputer Application, 1998,17 (8) :43-46. 